\title{
La Cumparsita: una fuente de pleitos Contursi y Maroni vs. Matos Rodríguez ${ }^{(* *)}$
}

\section{"La Cumparsita": a source of lawsuits Contursi and Maroni vs. Matos Rodríguez}

\begin{abstract}
Resumen: El presente artículo utiliza al Tango, a los pleitos y personajes que participaron en la elaboración de La cumparista y sus letras, como marco referencial para hablar sobre los derechos de autor y la propiedad intelectual. Además de opinar acerca del procedimiento para llegar a la solución final acerca de la adjudicación de los derechos de autor y los efectos de esta en cada uno de los beneficiarios, el autor nos cuenta un poco sobre el proceso de creación de esta composición musical así como el alcance que tuvo en su momento.
\end{abstract}

Palabras Clave: Tango - Derechos de Autor - Pleitos - Propiedad Intelectual - La Cumparsita - Arbitraje

\begin{abstract}
This article deploys Tango along with the lawsuits concerning to whom participated in the elaboration of "La Cumparsita" and its lyrics as a frame of reference for discussing about copyrights and intellectual property. In addition to giving an opinion about the procedure to arrive at the final solution related to the adjudication of the copyrights along its effects of that in each one of the beneficiaries, the author tell us a little bit of the process of creating this musical composition as well as the scope it had during its time.
\end{abstract}

Keywords: Tango - Copyright - Lawsuits - Intellectual Property - "La Cumparsita" - Arbitration

\section{Nace sin letra el tango más universal}

En fecha todavía discutida, pero seguramente en el verano del hemisferio sur de 1917 (Montero Aroca 2010) un joven entonces aún menor de edad, Gerardo Hernán Matos Rodríguez y en Montevideo, compuso la música del tango más universal. En aquellos tiempos el tango era más música para bailar que letra para oír, pues aunque se estaba ya en

$\left(^{*}\right)$ Catedrático de Direito Processual na Universidad de Valencia. Magistrado de la Sala de lo Civil y Penal del Tribunal Superior de Justicia de la Comunidad Valenciana. Correo electrónico: juan.montero@uv.es

${ }^{* *}$ Nota del Editor: El presente artículo fue recibido el 28 de setiembre de 2016 y su publicación fue aprobada el 30 de setiembre del mismo año. 
La Cumparsita: una fuente de pleitos

Contursi y Maroni vs. Matos Rodríguez

"La Cumparsita": a source of lawsuits

Contursi and Maroni vs. Matos Rodríguez las puertas no se había llegado todavía a lo que se llamará tango canción. Éste estaba a punto de aparecer, pero no adelantemos acontecimientos. También se estaba lejos de que el tango fuera música para escuchar.

Los carnavales de 1917 se acercaban en el tiempo y los integrantes de la Federación de Estudiantes del Uruguay estaban en la ruina. No es que precisaran, es que les urgía con extrema necesidad disponer de una musiquita, para con ella salir marchando por las calles de Montevideo con la esperanza de recoger algunas monedas que aliviaran la penosa situación económica de la asociación. Les habían embargado los muebles y les habían desahuciado de su local. La ruina no empañaba la alegría de los integrantes de una Federación de Estudiantes que se caracterizaban por estar matriculados en la Universidad -eso, sí-, pero por no aparecer por las aulas. La ruina los estaba dejando hasta sin local y sin él... dónde podrían ver pasar las horas sin estudiar.

En el local de la Federación había un viejo piano, propiedad de uno de sus miembros, no de la colectividad, y en ese piano, antes de que lo embargaran, es decir, a finales del mes de enero o a principios del mes de febrero de 1917, Gerardo Hernán Matos Rodríguez, con veinte años de edad y matriculado en la Facultad de Matemáticas de la Universidad del Uruguay, entretenía el tiempo aporreando las teclas. No sabía música, pero tocaba de oído o, como se dice en el Río de la Plata, tocaba de oreja. En ese aporrear el piano para entretenerse surgió una melodía, una marcha próxima al tango, que los estudiantes presentes aceptaron como musiquita estandarte en la búsqueda angustiosa de fondos. Con esa música los estudiantes desfilaron como comparsa en el carnaval de 1917 que se inició el 17 de febrero. Para desfilar no hacía falta que la música constara escrita en papel pautado, bastando tenerla en la memoria, pero pasado el carnaval algunos empezaron a pensar que de la misma podía salir algo. No sabían qué, pero algo. Por ello varias personas, que tampoco se caracterizaban por sus conocimientos teórico musicales, quisieron escribirla, pero hay que esperar a que en el mes de marzo llegue a Montevideo uno de los grandes del tango de la época, Roberto Firpo.
Estaba Firpo actuando con su cuarteto en una confitería-café, llamada La Giralda y sito en el centro de Montevideo, cuando se le acercó un grupo de estudiantes con un papel y le rogaron que tocara la que ya se llamaba La cumparsita. Firpo debió ver algo en aquella música pues, primero, la arregló musicalmente, es decir, la puso técnicamente en papel pautado ${ }^{(1)} \mathrm{y}$, luego, la tocó la noche de un viernes. Y con gran éxito. Tanto que se la hicieron repetir y el público sacó en hombros al joven compositor.

Casi inmediatamente tres conjuntos procedieron a grabar el tango. No importa ahora el orden de las tres grabaciones, pero fueron los cuartetos de Alonso-Minotto, de Firpo y de Juan Maglio, llamado comúnmente Pacho. Las grabaciones se hicieron muy pobremente, con los recursos técnicos del momento, y la música se oyó durante un poco de tiempo en los cafés de Buenos Aires, no mucho. La cumparsita pasó al olvido casi en el mismo año de su composición.

El tango se estaba aún oyendo por los cafés de camareras, un eufemismo para evitar la palabra adecuada, de Buenos Aires cuando Gerardo Matos vendió la propiedad de su obra. En los meses de abril y mayo de 1917 cedió la totalidad de los derechos a una empresa llamada Breyer Hermanos de Buenos Aires por 50 pesos argentinos, que se correspondían con 20 pesos uruguayos. El dinero no le duró en las manos. Todo se lo jugó en el mismo mes de mayo a un caballo en el hipódromo Maroñas de Montevideo y todo lo perdió.

Si alguien quiere saber que eran 20 pesos uruguayos, que fue la moneda en que se pagó La cumparsita, puedo decirle que era el equivalente de tres trajes de mediana calidad.

(1) Todo parece indicar que Firpo hizo algo más que escribir lo existente, pues está probado que escribió la tercera parte del tango partiendo de las notas de uno de sus tangos, La gaucha Manuela, pero el caso es que Firpo nunca reclamó nada respecto de la autoría de La cumparsita. Además en la primera parte introdujo unos solos de violín que convirtieron la musiquita caramente en un tango y lo hicieron menor marchoso pero más romántico. 


\section{Juan Montero Aroca}

Y si se tiene más curiosidad les diré que el caballo por el que se apostó se llamaba Skat, y que el ganador de la carrera fue Peri Jaune. Todos estos datos no sirven para nada, por lo menos jurídicamente, pero reconozcamos que nos sirven para ponernos en situación. Dan color al cuadro.

En cualquier caso lo que nos importa en este momento es que a mediados de 1917 el tango salió de la propiedad de su autor, Gerardo Matos, se incorporó a la propiedad de la Casa Breyer Hermanos, se publicó la partitura por esas fechas y el tango fue quedando en el olvido. En 1924 la propiedad del tango pasó a Ricordi Americana S. A., que había comprado todo el catálogo de Breyer. Pero esto ya no le importó al autor de la música; éste estaba en Paris gastando el dinero que tenía y el que no tenía.

Una noche de 1925 en un cabaret de Paris, donde actuaba la Orquesta Típica de Canaro, un abogado porteño, Pablo Calatayud, cayó en la cuenta de que Gerardo Matos en 1917 tenía 20 años y era menor de edad. Un menor de edad no puede realizar válidamente negocios jurídicos y a partir de ahí se produce la primera batalla legal entre Matos y Ricordi para recuperar la propiedad del tango. No se llegó a iniciar un pleito pero la editora musical prefirió llegar a un arreglo que se plasmó, primero, en el contrato de 1926, firmado en Buenos Aires, y por el que Matos accedió a algunos derechos, especialmente económicos, aunque Ricordi siguió siendo la dueña de la obra y, después, en el contrato de 1933, firmado en Paris, por el que Matos mejoró sustancialmente su posición jurídica y económica, tanto que puede decirse que asumió la mitad de los derechos de reproducción fonomecánica y de inclusión, una parte en la edición y, especialmente, todo el derecho de ejecución en Argentina y Uruguay.

Desde 1933 Gerardo Matos fue al menos copropietario de su obra, de una obra que generó muy importantes ingresos económicos.

\section{La invasión de Pascual Contursi en tangos ajenos}

Antes de 1917 algunos tangos tuvieron letra, pero la misma estaba sujeta a diversas influencias, especialmente al género chico español y, sobre todo, al cuplé (Puccia 1997) Las letras propiamente argentinas podían referirse a lo más chabacano ${ }^{(2)}$ del prostíbulo ${ }^{(3)}$ o a lo más típico del campo criollo(4). Y así estaban las cosas cuando llegó Pascual

(2) El 23 de noviembre de 1913 Leopoldo Lugones publicó en el periódico La Nación de Buenos Aires un artículo en que se contenían expresiones como estas: "... hay temas imposibles, dada su bajeza, y el tango es uno de ellos" (...) "danza prostituta" (...) "el objeto del tango es describir la obscenidad" (...) el tango "resume la coreografía del burdel, siendo su objeto fundamental el espectáculo pornográfico". Leopoldo Lugones (1874-1938) fue en su vida el espíritu de la contradicción; poeta y escritor, en la vida política pasó de una organización a otra con una facilidad que siempre ha desconcertado, pero que han dado otros muchos, desde el socialismo de joven al apoyo a las dictaduras de mayor. Fue el enemigo público del tango hasta que descubrió en 1926 el amor en la persona de María Emilia Cadelago, una casi adolescente, con la que mantuvo una relación de doce años y con la que aprendió a bailar el tango. Acabó suicidándose con un whiskey mezclado con cianuro cuando sus familiares le impusieron separarse María Emilia. Puede verse Eduardo Muslip, Fondo negro (Buenos Aires, 1997); Jorge Bocanegra, La pasión de los poetas (Buenos Aires, 2002). Ha sido Jorge Luis Borges quien ha elevado la figura de Lugones y lo ha puesto en lo más alto de la literatura argentina; así en el prólogo a El Hacedor (Buenos Aires, 1960), declarándose su heredero.

(3) Como decían los hermanos Bates "el tango vivió su infancia y buena parte de su pubertad en casas de baile de muy segundo orden, en 'peringundines' y lupanares. Las letras no hicieron más que reflejar el ambiente que les daba vida. Obscenas, procaces, indecibles en un medio, no diremos de cultura o de hogar, sino aun en la boca de personas de cierta educación, quedaron circunscritas a los muros que ocultaban la vergüenza de la ciudad" veáse Bates, Luis y Héctor, Historia del tango (Buenos Aires, 1936), 75.

(4) Sobre la letra y el tango existen algunas obras fundamentales, por ejemplo, Francisco García Jiménez, Así nacieron los tangos, 2a edición (Buenos Aires: Editorial Corregidor, 2006); Jorge Sareli, Libro mayor del tango (México, 1974); José Gobello y Eduardo Stillman, Las letras del tango de Villoldo a Borges (Buenos Aires, 1966); José Gobello y Jorge Bossio, Tangos, 
La Cumparsita: una fuente de pleitos

Contursi y Maroni vs. Matos Rodríguez

"La Cumparsita": a source of lawsuits

Contursi and Maroni vs. Matos Rodríguez

Contursi. Había nacido en 1988, en Chivilcoy, pero de niño emigró con sus padres a un conventillo de Buenos Aires. En 1914 una cuestión de faldas le llevó a Montevideo, donde permaneció hasta 1917. Murió en 1932 perturbada su mente.

Antes de Contursi los tangos podían tener letra, pero desde él esa letra pasó a ser una historia, una especie de relato en tres minutos, que casi siempre transmitía dolor o desesperanza, una sensación de tristeza por el amor traicionado o desengañado. Fue Pascual Contursi ${ }^{(5)}$ quien caracterizó al tango, quien le dio la tristeza de fondo, el sentimiento de despecho que ha arrastrado durante décadas; no es la ternura, en general, elemento propio del tango, aunque no falte en ocasiones cuando se canta a la madre (a la viejita); lo que lo caracteriza es la soledad, la desesperanza; es el retrato del hombre que apoyado en una esquina... espera, aunque no sabe ni qué ni a quién.
Pero empecemos por el principio. El tango en sus letras adquirió sentido propio, se individualizó respecto de otras músicas, cuando Pascual Contursi procedió a invadir con sus letras terrenos ajenos. El inicio de la invasión y de las letras del tango en el nuevo estilo se produjo entre 1915 y 1917 cuando Pascual Contursi le pone letra a varios tangos ajenos. Hubo algunos iniciales, pero la repercusión se inicia con el tango titulado Lita de Samuel Castriota al que le modificó el título llamándolo Mi noche triste ${ }^{(6)}$. En ese momento se produjo un gran cambio en el mundo del tango ${ }^{(7)}$, pero también empezaron los problemas de propiedad intelectual(8). Pascual Contursi ya había iniciado la invasión de los tangos ajenos y no le había ido mal. La

letras y letristas (Buenos Aires, 1975); Raúl, Outeda, La historia de 500 tangos (Buenos Aires, 1997); José Gobello, Letras de tango. Selección (1897-1981) (Buenos Aires, 1997); Oscar Del Priore e Irene Amuchástegui, Cien tangos fundamentales (Buenos Aires, 1998); Horacio Loriente, Ochenta notas de tango, Montevideo, 1998; Héctor Ángel Benedetti, Las mejores letras de tango (Buenos Aires, 1999); Juan Ángel Russo y Santiago Marpegan, Letras de tango, 1er vol. 1999 y 2 do vol. 2000 (Buenos Aires: Basílico); Eduardo Romano coord., Las letras del tango. Antología cronológica. 1900-1980, 5a edición (Rosario, 2000); Chab Norberto, 100 tangos con su historia, que no te podés perder (Buenos Aires, 2010).

(5) Sobre Pascual Contursi veáse G. J. Astarita, Pascual Contursi, Vida y obra (Buenos Aires, 1981); y G. Ruiz De Los Llanos, Pascual Contursi, 2ª edición (Buenos Aires, 1997).

(6) Mi noche triste ya descubre en su letra lo que iba a ser el tango en las décadas siguientes. Decía en su primera estrofa:

"Percanta que me amuraste

en lo mejor de mi vida,

dejándome el alma herida

y espina en el corazón,

sabiendo que te quería,

que vos eras mi alegría

y mi sueño abrasador,

para mí ya no hay consuelo

y por eso me encurdelo

pa'olvidarme de tu amor."

(7) Y siguieron Flor de tango (1918, de Augusto Gentile), Ivette (1920, de Augusto Berto y Julio Roca), La he visto con otro (de Antonio Scatasso), La mina del Ford (1924, de Antonio Scatasso y Fidel del Negro), y Ventanita de arrabal (1927, de Antonio Scatasso). La entrada de Carlos Gardel en el tango se hizo con letras de Pascual Contursi. Primero Mi noche triste en 1917, luego Flor de fango a finales de 1918. Al año siguiente, 1919, grabará el tercer tango De vuelta al bulin, letra de Pascual Contursi y música de José Martínez, y en 1920 Ivette, letra de Pascual Contursi y música de Enrique Costa y Julio Roca

(8) El poner letra a un tango ajeno, en este caso a Lita de Samuel Castriota, fue el principio de los problemas de Pascual Contursi con los compositores. En este caso se discutió, primero el título, pues si Castriota quería que se siguiera llamando Lita, Pascual Contursi se inclinaba por "Percanta que me amurastes"; al final se impuso la opinión de Carlos Gardel y de José Razzano: Mi noche triste. La discusión siguiente se refirió al reparto de los derechos de autor. Castriota quería imponer su 60 por 100 contra el 40 de Contursi, pero éste reivindicaba la mitad; en esa discusión Castriota llegó a afirmar: "¿Pero usted cree que ha escrito La dama de las camelias?". No había comprendido que la cuestión no era la calidad objetiva de la letra, sino si ésta había contribuido y en qué medida a la difusión del tango y, con ella, a la obtención de mayores ingresos dinerarios. 
Juan Montero Aroca

invasión, con todo, tendrá muchas más repercusiones con La cumparsita.

\section{La letra de Contursi a La cumparsita y la guerra de los veinticinco años}

En fecha y lugar no bien determinados, pero que pudo ser ya en 1917, Pascual Contursi le puso letra a La cumparsita y empezó a cantarla con acompañamiento de guitarra, precisamente en el cabaret del padre de Gerardo Matos, el Moulin Rouge de Montevideo ${ }^{(9)}$. Esto no tuvo trascendencia. Esta se inició realmente cuando en 1924 el tango con la letra de Contursi se incluyó en un sainete que se estrenó en Buenos Aires. En este momento es necesario incluir esa letra de Pascual Contursi:

"Si supieras

que aún dentro de mi alma

conservo aquel cariño

que tuve para ti.

Quién sabe si supieras

que nunca te he olvidado, volviendo a tu pasado

te acordarás de mí...

Los amigos ya no vienen

ni siquiera a visitarme,

nadie quiere consolarme

en mi aflicción.

Desde el día que te fuiste

siento angustias en mi pecho,

decí percanta, ¿qué has hecho de mi pobre corazón?

Al cotorro abandonado

ya ni el sol de la mañana

asoma por la ventana

como cuando estabas vos,

y aquel perrito compañero

que por tu ausencia no comía

al verme solo, el otro día,

también me dejó...

Sin embargo

te llevo en el recuerdo

con el cariño santo

que tuve para amar

y sos en todas partes

pedazo de mi vida

una ilusión querida

que no podré olvidar".

El 6 de junio de 1924 la compañía teatral de Leopoldo Simari(10) puso en el teatro Apolo una de esas obritas, que pueden calificarse de sainete, que estaba de moda. Ésta se llamaba Un programa de cabaret y era obra de dos personas, de Pascual Contursi y de Enrique Maroni. No se está seguro de que Contursi escribiera expresamente una letra de tango para esa obra, que tituló Si supieras, pues es perfectamente posible que la letra estuviera escrita unos años antes y que con ella hubiera actuado en el cabaret Moulin Rouge de Montevideo. Lo indudable es que La cumparsita por el año de 1924 estaba medio

(9) El padre de Gerardo, que se llamaba Emilio Matos, era hijos de españoles y era el propietario de un cabaret en Montevideo. En ese cabaret llamado Moulin Rouge había actuado Pascual Contursi durante dos o tres años, de 1915 a 1917, de modo ocasional. Este hecho fue una de las causas que originó, por lo menos en parte, la ira de Gerardo Matos. Contursi estaba en Montevideo cuando le escribió la letra a su tango y no le dijo nada. Existe un detalle muy difícil de aclarar a esta altura de los tiempos. Cuando empezó la disputa entre Matos Rodríguez y Pascual Contursi este aseguró que contaba con el permiso de Matos para realizar la letra. Esto debe ponerse en relación con la fecha en que Pascual Contursi escribió la letra, pues si la hubiera escrito en 1917 y la hubiera empezado a cantar en el cabaret del Padre de Matos Rodríguez, en el Moulin Rouge de Montevideo, no estaría tan claro que la letra se escribió sin conocimiento de Matos. Nada impide que Matos oyera la letra, cantada por Pascual Contursi, una noche de las muchas en que coincidirían en el cabaret y que no le diera importancia. Si esto fuera así la buena fe de Matos Rodríguez se pondría en cuestión cuando argumentó que en 1924 estaba en Paris y que por ello no pudo autorizar el añadido de la letra.

(10) Véase Osvaldo Pellettieri. 2002. Historia del teatro argentino en Buenos Aires, vol. II. La emancipación cultural. $1884-1930$. Buenos Aires, donde se recoge la mayor parte de las obras de Simari. 
La Cumparsita: una fuente de pleitos

Contursi y Maroni vs. Matos Rodríguez

"La Cumparsita": a source of lawsuits

Contursi and Maroni vs. Matos Rodríguez

en el olvido (11). Aunque el sainete sea de Contursi y de Maroni, la letra del tango fue solo obra de Contursi, y así lo admitió Maroni, aunque acabó cobrando y sus herederos lo siguen haciendo en la actualidad.

Rosario Infantozzi pone en labios de su tío abuelo estas palabras:

"De cualquier manera sentí mucha bronca porque lo menos que hubiera esperado era que me pidieran autorización para hacerlo, sobre todo teniendo en cuenta que Contursi trabajaba en el cabaret de mi padre en Montevideo ${ }^{(12)}$, por lo que no hubiera tenido ningún problema en buscarme y encontrarme. Me sentí invadido, o mejor aún, impotente, frente a este hecho consumado" (Infantozzi 2004: 95).

Sea una u otra la fecha de la letra, lo cierto es que Gerardo Matos hubo de guardar silencio en 1924 cuando el tango se interpretó en un escenario y cuando lo grabó Carlos Gardel. Si Matos no era el propietario del tango, que estaba vendido a Breyer Hermanos, nada podía aducir. Las cosas van a cambiar con el contrato de 1926 entre Ricordi y Matos. En ese contrato, de 2 de septiembre de 1926, Matos se compromete jurídicamente a escribir una letra para el tango y a ceder la propiedad de la misma a Ricordi; es decir, la letra sería de su autoría, pero no de su propiedad. La letra efectivamente se escribió, y estuvo presta el 9 de noviembre de $1926^{(13)}$. Se inicia aquí el ataque defensivo frente a la invasión, pues inmediatamente se requirió a la entonces Asociación Argentina de Autores y Compositores para que impidiera que se tocara La cumparsita con letras o versos que no fueran los originales.

Esa defensa tuvo diversas manifestaciones exteriores, todas ellas dirigidas a las sucesivas entidades de gestión de derecho de la propiedad intelectual, y todas en el sentido de prohibir que se tocara su música con la letra de Contursi. Las dichas manifestaciones son muy variadas pero nos limitaremos a poner unos ejemplos, pues una guerra se sustancia bien en incidentes menores, bien en batallas, y no es preciso que la historia recoja todos los enfrentamientos para tener una idea general. Lo que importa en el final de la guerra:

1) José de (a veces di) Clemente, que fue miembro de la Comisión provisoria inicial del Círculo Argentino de Autores y Compositores de Música ${ }^{(14)}$, se dirigió por escrito a Gerardo Matos en 1934 intentando propiciar un acuerdo de este con los autores de la letra. Matos ni contestó. Y empezó a dar muestras de una cierta posición de intransigencia ${ }^{(15)}$.

(11) Debe tenerse en cuenta que el añadido de la letra supuso una leve alteración en la música, para lo que Contursi contó con la ayuda de Antonio Scatasso (1886-1956), que era el director musical de la obra teatral, por mucho que se ha puesto en cuestión si llegó a saber música o si tocaba "de oreja". En esa obra el tango lo cantó primero Juan Ferrari y luego Carlos Carranza.

(12) Si se alude a que Pascual Contursi "trabajaba en el cabaret de mi padre en Montevideo" se está refiriendo a mucho antes de 1924, nada menos que a los años de 1915 a 1917, que son aquellos en los que Pascual Contursi sí trabajó en el Moulin Rouge. Fue entonces cuando lo pudo "buscar y encontrar". No tendría sentido que lo buscara en 1924 cuando estaba en Paris.

(13) Esta letra no la vamos a incluir porque, primero no es necesario y, después y sobre todo, porque Infantozzi hace decir a su tío abuelo Gerardo Matos estas palabras: letra "que es un espanto, mal parida, escrita sin ganas y a regañadientes". Se trataba de tener argumentos para oponerse a la letra de Pascual Contursi, Véase Infantozzi, De Matos Rodríguez, La cumparsita, 105.

(14) El Círculo Argentino de Autores y Compositores de Música se fundó en 1930 con el fin de recaudar el derecho de ejecución del pequeño derecho y al mismo pertenecía Gerardo Matos. Uno de los que fundaron el Círculo fue este José de Clemente.

(15) En carta dirigida por Gerardo Matos a su cuñado Enrique Durán Guani (Coto) el 6 de junio de 1939, desde Buenos Aires a Montevideo le decía: "Me he peleado con la Glücksmann, con la Columbia, con la Brünswick, con la Ricordi, con el editor de Brasil, con el editor de España y sólo me queda más o menos regular la relación con la Victor y el editor Perrotti"; véase en Infantozzi, De Matos Rodríguez, La cumparsita, 126. 
Juan Montero Aroca

2) En 1940 Matos como socio de la Sociedad Argentina de Autores y Compositores se dirigió por carta a su presidente Francisco Canaro(16) protestando de unas declaraciones hechas en la radio por Enrique Maroni.

3) Ya en 1941, es decir, muerto hacía tiempo Pascual Contursi, su viuda, Hilda Briano, se dirigió por carta dos veces a Gerardo Matos en búsqueda de una solución amistosa. No se sabe que Matos contestara.

4) En junio de 1942 Gerardo Matos volvió a prohibir de modo tajante, en telegramas tanto a SADAIC como a Odeón, que se procediera a la ejecución de su tango con cualquier añadido de letra o recitación diferente de la letra de su propia autoría. Esta prohibición se refería de modo principal, y casi único en aquel momento, a la grabación de Carlos Gardel en 1928, y ello suponía algo muy grave pues Gardel era el ídolo muerto que estaba más allá de cualesquiera críticas.

De este modo se puede ir haciendo relación una larga serie de incidentes, todos ellos bélicos, entre Gerardo Matos, por un lado y, por el otro, Hilda Briano de Contursi y José María Contursi, en tanto que herederos de Pascual Contursi, y Enrique Maroni. De ellos dijo Francisco Canaro: "Y resultó que a pesar de los reiterados requerimientos y gestiones de Contursi y Maroni para que Matos Rodríguez aceptara su colaboración en el tango, éste se mantuvo siempre empecinado en la negativa, que con el tiempo motivó un pleito" (Canaro 1999: 293).

\section{Dos procesos contra Gerardo Matos}

En realidad la guerra declarada entre letristas y compositor dio origen, no un proceso, sino a dos: a) El primer proceso, con demanda en 1946, se produjo entre Hilda Briano (de Contursi) y José María Contursi ${ }^{(17)}$, herederos de Pascual Contursi, y Enrique Maroni como demandantes, contra Gerardo Matos, que fue el único demandado, y le correspondió al Juzgado de Primera Instancia en lo Civil No. 5 de los de esa Ciudad, donde era titular el doctor Raúl Lozada Echenique y secretario el doctor Antonio Collazo. En ese proceso la demanda contenía dos pretensiones, una de daños y perjuicios y otra de reconocimiento de derechos de coautores y cobro de pesos.

La búsqueda de ese proceso nos ha hecho conocer la ciudad de Buenos Aires. Hemos ido desde el Archivo Judicial, en los sótanos siniestros de la Corte Suprema, en la que hemos sido tratados de modo que hay que gradecer públicamente, hasta en los despachos de los descendientes de los abogados que hubieran podido intervenir en el pleito. $Y$ hemos llegado a una conclusión: El mejor modo de conocer una ciudad es buscar un proceso de hace más de cincuenta años. Puede que al final no se encuentre, como nos ha sucedido a nosotros, pero es muy ilustrativo, no ya de la vida judicial, sino de la vida en general de una ciudad, de sus barrios y de sus calles $\mathrm{y}$, sobre todo, de sus personas.

En el Archivo Judicial quedó aclarado que los procesos en los que se ejercen

(16) En 1936 se produjo la fusión entre el Círculo Argentino de Autores y Compositores de Música y la Asociación Argentina de Autores y Compositores de Música, dando lugar a la Sociedad Argentina de Autores y compositores de Música (en adelante, "SADAIC") de la que era socio Gerardo Matos y Francisco Canaro presidente.

(17) Si las letras de Pascual Contursi abrieron una nueva etapa en el tango, las de su hijo José María (1911-1972, apodado Catunga, a veces con K) no le fueron a la zaga. Basten estos títulos: Cada vez que me recuerdes, Como dos extraños, En esta tarde gris, Gricel, Han pasado los años, Sombras... nada más. Un esbozo de su figura puede verse en Montero Aroca, Juan. 2010. Bolero. Una historia cantada en 150 emociones. Valencia: Tirant lo Blanch. Dijimos allí: "Si el padre se ríe de la vida para ridiculizarla y en sus letras usa normalmente del lunfardo; el hijo se toma las cosas más en serio y ya no utiliza el argot porteño. El hijo es un poeta que tiene una musa inspiradora Gricel, a la dedica buen parte de su obra, mientras que el padre fue un bohemio y piensa más en las minas, en plural. El hijo tiene, claramente, una cultura mayor y se expresa poéticamente". Veáse a Flores Montenegro, R. Amor en el tango. Gricel-José Ma Contursi (Buenos Aires, 2005). 
La Cumparsita: una fuente de pleitos

Contursi y Maroni vs. Matos Rodríguez

"La Cumparsita": a source of lawsuits

Contursi and Maroni vs. Matos Rodríguez pretensiones declarativas y de condena a pagar una cantidad de dinero se destruyen a los treinta años de su finalización. Es una lástima que esa destrucción no suponga un verdadero expurgo, es decir, una discriminación entre lo que puede destruirse por inútil y lo que merece conservarse por razones muy variadas, como puede ser el interés histórico. Un proceso entre los autores de La cumparsita debería haber merecido ser excluido del pasto de las llamas en la purificación por el fuego del archivo. Pero así son las cosas.

En los despachos de abogados no hubo más suerte. Empecemos por decir que al principio no teníamos noticia del abogado que defendió a los demandantes, que después llegamos a tener un nombre, el del doctor Carlos Gregorio Menica, abogado de Enrique Maroni, avanzada ya la investigación, pero que por ese camino no encontramos salida. Desde el principio sabíamos quién fue el abogado del demandado, el mismo doctor Pablo Calatayud que sirvió los intereses de Gerardo Matos en 1926 para la recuperación de los derechos. Ahora bien, este despacho de abogados se cerró en 1976, Calatayud no tuvo un hijo abogado y nadie parece haberse hecho cargo de los papeles de los viejos asuntos. Otro camino sin salida.

b) El segundo proceso, iniciado en abril de 1947, se inició por José Razzano, como demandante, contra Gerardo Matos como demandado y contenía una única pretensión de daños y perjuicios. Esta segunda demanda requiere alguna explicación para los no versados en la vida de Gardel. Se trata de recordar dos cosas, una sobradamente conocida, y la otra no tanto.

c) En los inicios de la vida artística de Carlos Gardel, allá por el año 1911, se encontró con José Razzano, nacido en el Uruguay y conocido como el oriental con el que formó un dúo, para la interpretación de canciones criollas, que actuó hasta que Razzano perdió la voz a finales de
1925. Razzano se convirtió entonces en el apoderado de Gardel y así permaneció hasta 1931 en que se produjo la ruptura. Si se atiende a las primeras grabaciones de Gardel, no las de $1912^{(18)}$, pero sí a partir de $1917^{(19)}$, se advertirá que hay muchos dúos con Razzano y que la mayor parte de las canciones han sido compuestas por los dos. Sólo los tangos fueron cantados siempre en solitario por Gardel.

d) Muerto Gardel en 1935 todos sus derechos, bien como autor bien como intérprete, los heredó su madre, Berta Gardes y, muerta ésta el 7 de julio de 1943, el heredero fue, según un testamento ológrafo, Armando Defino, el último apoderado de Gardel, un amigo de la juventud. No vamos a entrar en las pretensiones de Razzano sobre los derechos de sus obras en colaboración con Gardel, pero el caso fue que, después de una negociación desarrollada en un almuerzo con Francisco Lomuto, Mario Bérnard y Francisco Canaro, se llegó al acuerdo de que Defino cedía los derechos a cambio de una indemnización de 30.000 pesos $^{(20)}$.

De este modo Razzano se convirtió en titular de los derechos y en ese concepto demandó a Gerardo Matos. El sentido de la demanda era éste: Matos había impedido, desde 1926, pero sobre todo desde 1942, que Odeón, la discográfica de Gardel, pusiera a la venta los discos de éste en que grabó La cumparsita con letra de Contursi y con ello había causado un daño patrimonial al titular de esos derechos que era Razzano, por lo que éste pedía en su demanda la indemnización por esos perjuicios.

(18) Véase Benedetti, Héctor Ángel, Gardel en 1912. Historia de sus primeras grabaciones (Buenos Aires: Éditions de la Rue du Canon d'Arcole, 2005).

(19) La obra fundamenta es la de Morena, Miguel Ángel, Historia artística de Carlos Gardel, 5a ed. (Buenos Aires: Editorial Corregidor, 2008).

(20) Veáse Francisco, Dijo Canaro, Mis memorias. Mis bodas de oro con el tango (Buenos Aires: Editorial Corregidor, 1999), 295: "En virtud de esa transacción generosa y caballeresca, Razzano realizó un negocio sin precedentes en los anales de nuestra entidad autoral (es la SADAIC), pues, por una suma de treinta mil pesos moneda nacional, adquirió la propiedad de un repertorio que representa una fortuna incalculable". 
Juan Montero Aroca

Este segundo proceso se empezó a tramitar ante el Juzgado de Primera Instancia en lo Civil a cargo del doctor César A. Fauvety y secretaría No. 26 del doctor Rafael M. Demaria. Naturalmente fue echado a las llamas treinta años después, y sobre su búsqueda puede repetirse lo que hemos dicho antes respecto del proceso primero, pero ya en tono menor pues con el primero aprendimos y no incurrimos en los mismos errores.

Ninguno de los dos procesos terminó con sentencia. En el primero, una vez muerto Gerardo Matos, las partes acordaron someterse al arbitraje del presidente de la SADAIC, Francisco Canaro, y en el segundo, a la vista de lo anterior, Razzano desistió para que todo se desarrollara pacíficamente.

\section{El arbitraje en general y su base en la libertad}

El proceso primero estaba en marcha casi dos años, sin que en el mismo se llegara a dictarse sentencia, cuando se produjo un acontecimiento fundamental: el 25 de abril de 1948 murió Gerardo Matos y se abrieron nuevas posibilidades. Estando bien acompañado había sufrido una hemiplejia en agosto 1944 que le había paralizado el lado izquierdo del cuerpo y que, sobre todo, había acentuado su incapacidad para aceptar arreglos basados en el pacto y la transacción. Por eso en los dos procesos mantuvo una posición intransigente en lo que creía su derecho. Con su muerte se produjo una nueva situación.

Gerardo Matos había muerto sin testamento, pero ello no supuso problema alguno dado que tenía una única heredera legítima: su Madre, Edelmira Rodríguez. Ahora bien, ésta se encontraba limitada intelectualmente y por ello su otra hija, Ofelia Isis Matos, puso inmediatamente en marcha la declaración de incapacidad. En el expediente "Rodríguez de Matos, Edelmira Agustina- Incapacidad- L ${ }^{\circ} 36, \mathrm{~F}^{\circ}$ 9" se dictó por el Juez Letrado de Primera Instancia en lo Civil de Sexto Turno de la ciudad de Montevideo auto de 30 de junio de 1948 nombrando curadora a Ofelia. Fue ésta, pues, la que a los pocos meses de la muerte de Gerardo Matos tenía las riendas de una posible negociación.

A estas alturas no debería ser necesario que en un trabajo de esta naturaleza se escribieran unos párrafos sobre el sentido del arbitraje, pero es el caso que, en nuestra opinión, en los últimos años se ha iniciado un camino en la comprensión del arbitraje que es profundamente erróneo y que ha conducido al fracaso de la institución; se ha pretendido entender al arbitraje como medio para reducir la sobrecarga de trabajo de los tribunales. El error se advierte de modo muy claro en la exposición de motivos de la española Ley 36/1988, de 5 de diciembre, de Arbitraje, cuando asume lo que se dice que el Comité de Ministros del Consejo de Europa, Recomendación 12/1986: Ios gobiernos deben adoptar las disposiciones adecuadas para que en los casos en que se presten a ello, el arbitraje pueda constituir una alternativa más accesible y más eficaz a la acción judicial.

El arbitraje se concibe de esta manera como un medio alternativo a la justicia del Estado, como instrumento para aliviar la sobrecarga de trabajo de los tribunales. $Y$ ello reside un gravísimo error. El arbitraje no es una alternativa a nada, pues el arbitraje es expresión de libertad frente a estatismo. Se trata de que el ciudadano sea capaz de resolver sus propios problemas acudiendo a la disposición de sus derechos materiales, de que no todo esté en la manos de para-estado que decide los conflictos de sus súbditos, entendido estos no como ciudadanos libres, sino como menores de edad o incapaces.

Las constituciones de los diferentes países reconocen a los ciudadanos el derecho a acudir a los tribunales del Estado para que éstos les tutelen en sus derechos e intereses. Esto es lo que dispone, por ejemplo, el artículo 24.1 de la Constitución española de 1978 cuando dice que "todas las personas tienen derecho a obtener tutela efectiva de los jueces y tribunales en el ejercicio de sus derechos e intereses legítimos". Seguidamente las constituciones proceden a poner las bases de la organización del poder judicial y dicen que la función jurisdiccional, es decir, aquella tutela efectiva, corresponde prestarla a los tribunales los cuales asumen de modo exclusivo el juzgar y el hacer ejecutar lo juzgado. Se configura 
La Cumparsita: una fuente de pleitos

Contursi y Maroni vs. Matos Rodríguez

"La Cumparsita": a source of lawsuits

Contursi and Maroni vs. Matos Rodríguez

de este modo primero un derecho de los ciudadanos, poder pedir justicia, y luego un deber del Estado, personalizado en los tribunales del mismo, proceder a prestar y a hacer efectiva esa justicia.

Este conjunto de derecho y de deber no impide algo que se corresponde con la libertad misma. Una cosa es que el ciudadano tenga el derecho de pedir justicia a los tribunales y otra muy distinta sería que no pudiera acudir a otros sistemas de solucionar los conflictos que surgieran entre ciudadanos. Las constituciones de contenido verdaderamente liberal han partido siempre de dos principios: i) El Estado asegura a sus ciudadanos que les prestará su justicia cuando les haga falta; $y$, ii) Pero ese mismo Estado reconoce que sus ciudadanos pueden acudir a otros medios para solucionar sus conflictos. Y el medio mejor es el arbitraje.

En la primera Constitución española, la de 1812 que fue votada por los diputados argentinos, se decía, por un lado, en el artículo 242 que "la potestad de aplicar las leyes en las causas civiles y criminales pertenece exclusivamente a los tribunales" pero seguidamente se añadía, en el artículo 280 , que "no se podrá privar a ningún español del derecho de terminar sus diferencias por medio de jueces árbitros, elegidos por ambas partes". Y en la Exposición de Motivos se afirmaba rotundamente: "El derecho que tiene todo individuo de una sociedad a terminar sus diferencias por medio de jueces árbitros está fundado en el incontrastable principio de la libertad natural".

Desde las consideraciones anteriores en todos los países del mundo occidental se ha regulado el arbitraje y lo han hecho bien en el código procesal civil bien en una ley específica. A nuestros efectos ello es indiferente, como también lo es la concreta manera de cómo se regulaba el arbitraje en Argentina en 1948, aunque debe tenerse en cuenta que se trató entonces de la aplicación del Código Procesal Civil de la Nación. Lo que nos importa es que, muerto Gerardo Matos, la heredera fue su madre Edelmira, y que estando esta declarada incapaz, su hija Ofelia, como su curadora en la legislación uruguaya, llegó junto con los demandantes, que eran Enrique Maroni y, muerto Pascual Contursi en 1932, su viuda Hilda Briano y su hijo José María, al acuerdo de someter todo el asunto al arbitraje de Francisco Canaro que era, en aquel momento, el presidente de la SADAIC.

\section{La SADAIC y Francisco Canaro}

Para entender este concreto arbitraje, y precisamente de Francisco Canaro, puede ser conveniente dar noticia de la SADAIC, es decir de la Sociedad Argentina de Autores y Compositores de Música, y de cómo se constituyó y también serán convenientes algunas palabras sobre Francisco Canaro ${ }^{(21)}$.

En el origen de todo está la indefensión de los autores y compositores. En 1918, el entonces gerente de Breyer Hermanos, Sr. Guillermo Fischer, instó una reunión en la sede de esta entidad para constituir la que se llamó Sociedad Nacional de Autores, Compositores y Editores de Música. Fue un error; los intereses de los editores eran contradictorios con los de los autores y compositores. En 1920 apareció así la Asociación Argentina de Autores y Compositores de Música, que se domicilió en la casa de Canaro. La luchas internas dieron lugar a que se escindiera de esta entidad el Círculo Argentino de Autores y Compositores de Música que se constituyó en 1930, siendo presidente del mismo el omnipresente Canaro. El éxito primero de la entidad fue la Ley 11.723 , de 26 de septiembre de $1933^{(22)}$, que se debe a los trabajos de

(21) Véase Francisco Canaro, Mis memorias. Mis bodas de oro con el tango, 244 y siguientes., con la historia de la SADAIC.

(22) Esta Ley sigue en vigor, aunque con varias modificaciones. En esa Ley 11.723 disponía el artículo 5: "La propiedad intelectual corresponde a los autores durante su vida y a sus herederos o derechohabientes, durante treinta años más". Después de la Ley 24.870, de 16 de septiembre de 1997, ese artículo 5 dice: "La propiedad intelectual sobre sus obras corresponde a los autores durante su vida y a sus herederos o derechohabientes hasta setenta años contados a partir del 1 de Enero del año siguiente al de la muerte del autor". Esa Ley 24.870 es la llamada Ley La Cumparsita, pues se dio atendiendo que los 


\section{Juan Montero Aroca}

Mario Bernard (El Flaco), que luego fue director general de SADAIC.

Después de todas las luchas internas, los argentinos descienden de españoles y la sangre italiana injertada no ha limado el defecto de encontrar enemigos en casa propia, se llegó el 9 de junio de 1936 a la creación de una única entidad, la Sociedad Argentina de Autores y Compositores de Música (SADAIC) que inicialmente presidió Francisco J. Lomuto, pero que ya en 1937 pasó a presidir Francisco Canaro, que fue su presidente de modo casi continuado y que lo era en los meses iniciales de 1948.

Francisco Canarozzo, conocido como Canaro (1888-1964), fue uno de los grandes del tango, distinguiéndose menos como violinista, más como compositor $\mathrm{y}$, sobre todo, como director de orquesta. Nació en Uruguay, hijo de sepulturero, y pronto con su familia se trasladó a Buenos Aires, donde su padre trabajaba de albañil. Se nacionalizó argentino en 1940. En sus inicios se asoció con dos grandes del tango: Vicente Greco, primero, y luego con Roberto Firpo, pero muy pronto puso en marcha su negocio de las orquestas, de las que tenía normalmente cuatro funcionando al mismo tiempo. Fue un empresario, pero de los de los tiempos viejos, un hombre de una sola palabra.

Se suele decir que su ingente obra de composición es dudoso que sea toda de él, pero los que ponen en duda su autoría no ofrecen más que su opinión, sin añadir otros elementos de juicio. Es sólo una murmuración, no sé si decir que es de envidiosos. Entre estas obras hay algunas que han pasado a la historia de la música, como Sentimiento gaucho, La última copa (las dos con letra de Juan Andrés Caruso), Madreselva (letra de Luis César Amadori) o Adiós, Pampa mía (letra de
Ivo Pelay y colaboración en la música con Mariano Mores).

Algunas de las innovaciones en el tango se deben a él. Por ejemplo la introducción del contrabajo en la orquesta o del cantante, si bien éste no para cantar toda la letra sino sólo el estribillo del tango o de la canción, dando lugar a los llamados estribillistas, el primero de los cuales fue Roberto Díaz (realmente Roberto Pablo Carvalho, 1900-1961).

Si tuvo éxito con la música, lo tuvo también con el dinero que ganó(23). Era común decir: "Tiene más plata que Canaro", y se cuenta que estando en el hipódromo Palermo de Buenos Aires Carlos Gardel le pidió 500 pesos, que debía ser una cantidad muy importante, y Canaro se la entregó en el acto y para no ser devuelta, aunque el mismo Canaro asegura que unos años después se la pidió y Gardel le contestó: “¿No tenés vergüenza con el paco que tenés pedirme los 500 mangos?": Lo de paco hace referencia al dinero ahorrado.

Al mismo tiempo que tuvo un gran éxito como empresario musical fue el principal defensor de los derechos de propiedad intelectual de los músicos. Todas las entidades de defensa de éstos fueron encabezadas por él. Lo hacía con una actitud casi dictatorial, pero hasta su muerte en 1964 fue casi el permanente presidente de la SADAIC, si bien dejó que, en fases pequeñas y transitorias, otros asumieran la que consideraba que era su presidencia.

derechos sobre este tango se terminaban en 1998, es decir a los 50 años de la muerte de su autor, muerte que se produjo en 1948. Naturalmente benefició a otros, como al hijo de Homero Manzi, Acho Manzi, pues, muerto aquél en 1951 , los 50 años vencían en 2001 y ahora vencerán en 2021.

(23) Canaro asumía todos los riesgos económicos tanto con las orquestas como en los espectáculos teatrales, de modo que los integrantes de las orquestas cobraban sueldo mensual, trabajaran más o menos, pero no participación ni en los beneficios, ni en las pérdidas. Se ha llegado a decir que también tenía a sueldo a los autores del texto de las comedias musicales, como Juan A. Caruso e Ivo Pelay. En todo ganó mucho dinero, salvo cuando se metió en el negocio del cine, en el que él decía: "Como productor cinematográfico no tuve suerte"; en realidad no fue cuestión de suerte, sino de que las películas que produjo eran malísimas. A su muerte la murmuración de la calle lo que discutía eran los millones de la herencia; la sorpresa vino cuando en el testamento dividió la herencia entre su familia, digamos legal, y dos hijos extramatrimoniales; véase Francisco García Jiménez, Memorias y fantasmas de Buenos Aires (Buenos Aires: Editorial Corregidor, 1994), $281-287$. 
La Cumparsita: una fuente de pleitos

Contursi y Maroni vs. Matos Rodríguez

"La Cumparsita": a source of lawsuits

Contursi and Maroni vs. Matos Rodríguez

\section{El arbitraje, el laudo de Canaro y sus insuficiencias}

En los archivos de la SADAIC, y en el expediente de $L a$ cumparsita, no están los documentos de cómo se confío a Canaro el arbitraje, aunque es manifiesto que en éste, en el arbitraje, concurrieron varios graves inconvenientes:

a) No queda claro en la documentación si lo que se pactó por las partes fue un arbitraje ritual u otro irritual, aunque todo parece indicar que se trata de lo segundo. De la misma manera sí está claro que no se trató de un arbitraje de derecho, sino de otro de equidad; lo que en Argentina se llama de amigables componedores. Canaro no sólo no era abogado, sino que había pasado muy poco tiempo por la escuela elemental.

b) Lo peor de todo es que siendo el arbitraje y el laudo una especie de continuación de un proceso entre partes determinadas, únicamente estas partes fueron las que se sometieron al arbitraje. En los derechos de propiedad intelectual de La cumparsita había en 1948 interesados que no estuvieron en el arbitraje, y de modo más destacado la entidad Ilamada Editorial Ricordi Americana, la cual era titular de una parte muy importante de los derechos.

c) Por si falta algo debe advertirse que José Razzano, el demandante en el segundo proceso de que hemos hecho antes mención, tampoco fue parte en el arbitraje. Razzano había desistido de su proceso para no ser obstáculo, pero no se convirtió en parte en el arbitraje, lo que no impidió que en el laudo existiera pronunciamiento a él relativo.

Con estos males antecedentes Canaro dictó su laudo, lo que él llamó Fallo Arbitral el 10 de septiembre de 1948 y el mismo día es aceptado por todas las partes que firman su conformidad $^{(24)}$, sin expresar reparo alguno(25). El laudo es conocido porque el propio Canaro lo hizo público en sus Memorias ${ }^{(26)}$.

La controversia, más fáctica que jurídica, entre los autores de la letra y el autor de la música, puede sintetizarse así: ¿Contribuyó la letra de Contursi a la difusión y éxito de La cumparsita? Si la respuesta es positiva la conclusión debe ser que los autores de la letra deben participar en los beneficios que se obtengan con todos los derechos propios de la propiedad intelectual. Si la respuesta es negativa esa participación carece de sentido. La respuesta que dio Francisco Canaro, conforme a su leal saber y entender, consistió en que la letra contribuyó al éxito de La cumparsita y de ahí el contenido económico del laudo.

Canaro en su posterior libro de memorias ${ }^{(27)}$ hizo una especie de fundamentación del laudo al decir que poco después de estrenada y grabada La cumparsita él la tocaba con su orquesta, pero que tuvo un éxito efímero, y añade:
"Pero lo curioso es que al tiempo se repuso en los repertorios, se 'reestrenó', como se dice en jerga teatral; volvieron a ejecutarlo las orquestas de moda, se hicieron nuevas grabaciones de discos, la empezó a cantar Gardel como uno de sus números predilectos y continuaron difundiéndola cancionistas y cantores. $Y$ así comenzó una nueva era para el inspirado tango, que

(24) El 16 de septiembre de 1948 el laudo es protocolizado, es decir, es incluido en el protocolo notarial, por el letrado de Enrique Maroni, doctor Carlos Gregorio Menica.

(25) Luego en el citado libro de Rosario Infantozzi, en la página 201, se dirá: Canaro "aunque sabía mucho de tangos, muy poco sabía de leyes. Presionado por todos lados, pronunció el laudo final, de muy cuestionable justicia. Mi abuela, la famosa Becha, a quien le sobraba decencia y le faltaba ambición, lo aceptó".

(26) Realmente en el libro de memorias de Canaro el laudo es prácticamente ilegible, dada la pésima calidad de las fotocopias de la página 294. Por eso hubimos de acudir a la calle Lavalle, 1545, sede de la SADAIC en Buenos Aires, para solicitar una fotocopia legible, de esa fotocopia proviene el escaneado de las páginas que se ofrecen en el texto. Hay que agradecer aquí a la doctora María Alicia Muract Gola el interés que se tomó para que llegara a disponer de un texto legible.

(27) Véase Francisco Canaro, Mis memorias. Mis bodas de oro con el tango (Buenos Aires: Editorial Corregidor, 1999). 


\section{Juan Montero Aroca}

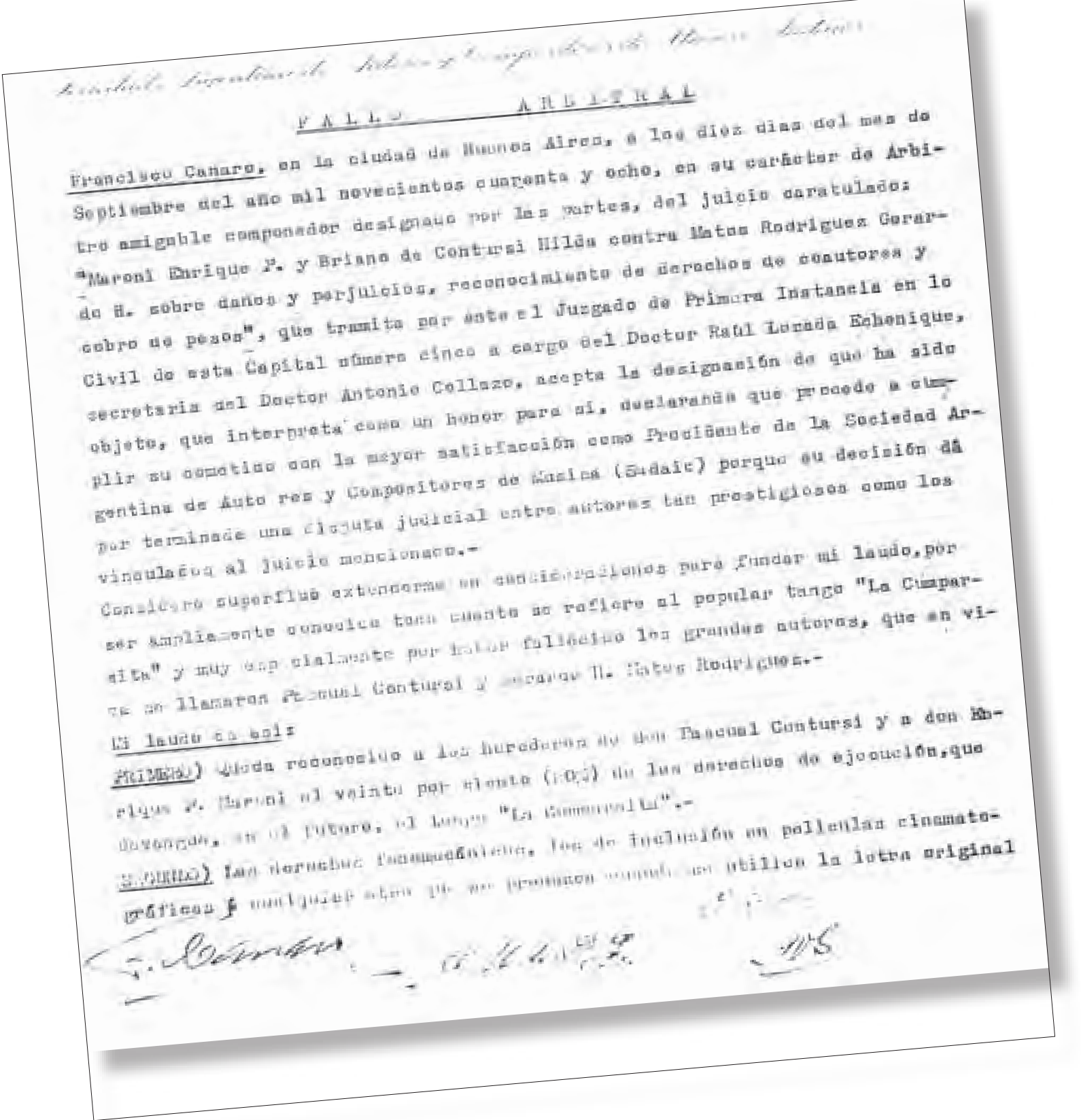


La Cumparsita: una fuente de pleitos

Contursi y Maroni vs. Matos Rodríguez

"La Cumparsita": a source of lawsuits

Contursi and Maroni vs. Matos Rodríguez

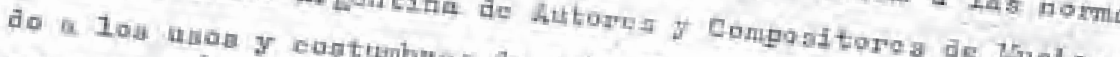

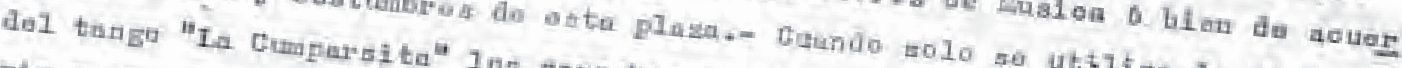

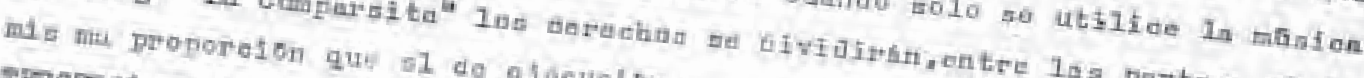

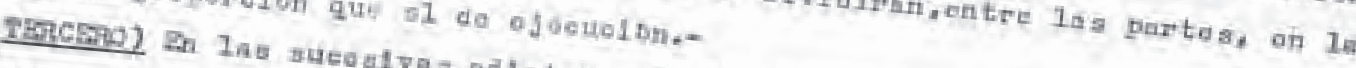

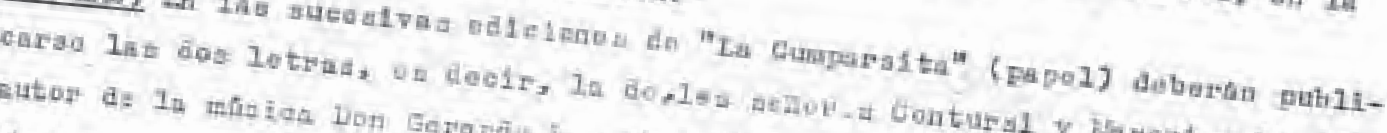
otro.-

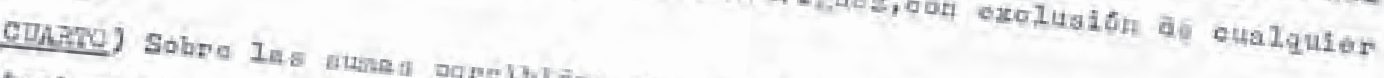

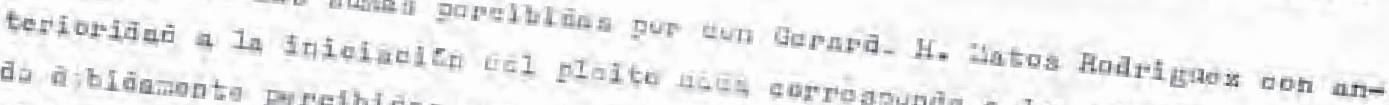

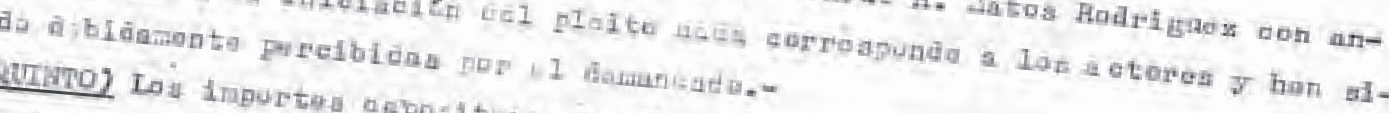

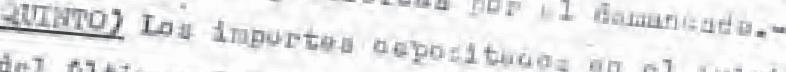

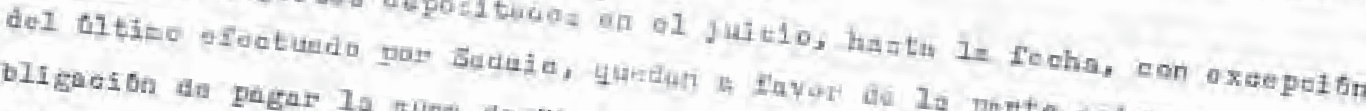

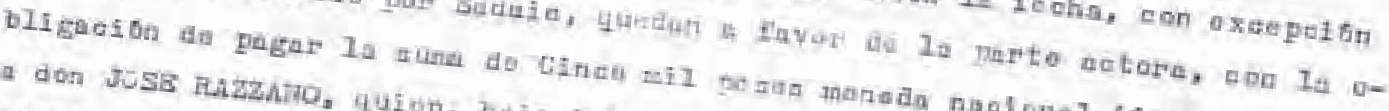

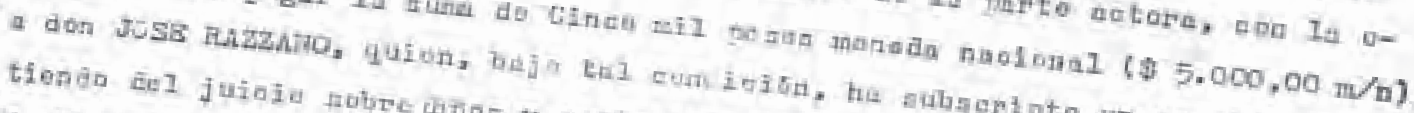

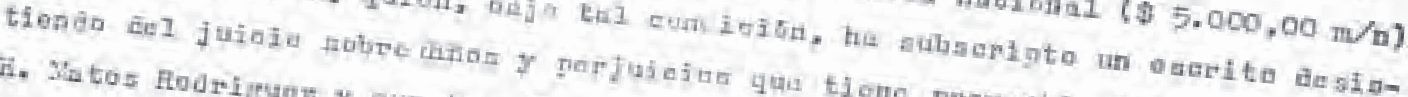

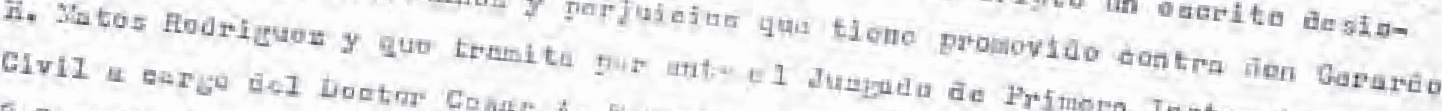

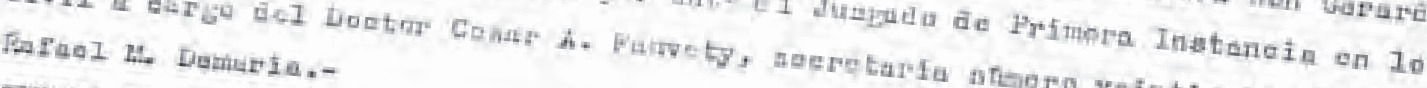

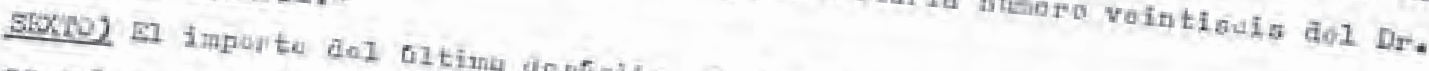

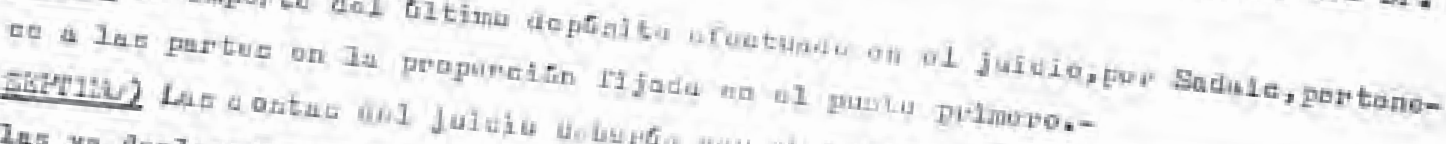
Ias ya beelarndae on ol jaletox- 


\section{(AB)}

\section{Juan Montero Aroca}

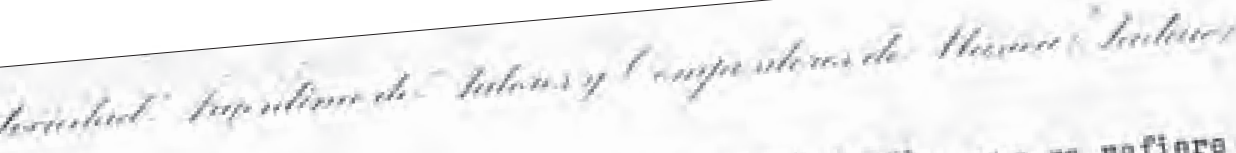

ocravo) Se aclare que el velutis por clento (20\%) a que se rafiero al artroulo prinero, onnprendo lin participacion total de los heroderos de don Pagoual Contursi y de dón Znrique P. Waroni y quo tanto esta partioipacion sorio. In que corrosponda par atulquier otro concepto, se ropurtiraso por pertes iguales entre los herederos de don Pusoual Contursi $y$ don Dhrique 2. Laroni.-
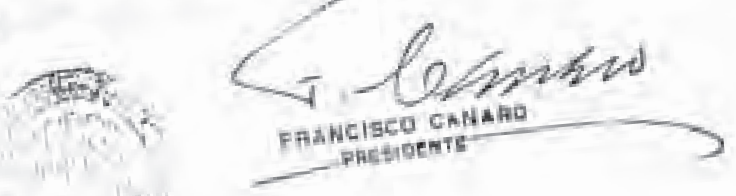

La partes presentes se notifican, prastan sut total oprifuraidad y agredecen aI Sefroz Franolsco Canuro $y$ a In Sociedad Argentina de

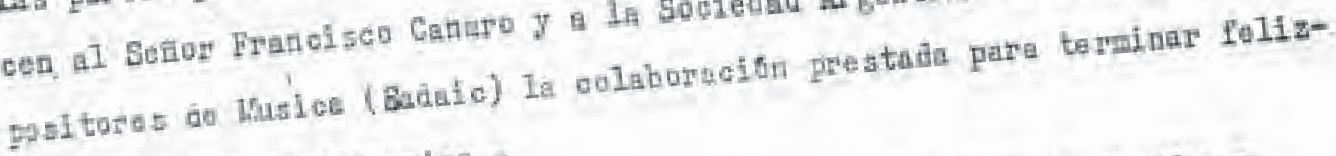
mento todas sugdiforncias:-

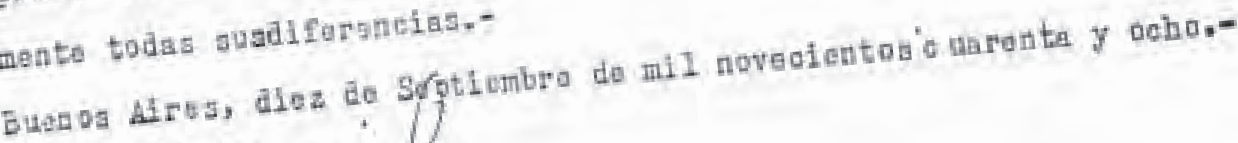
Esicisur harmil

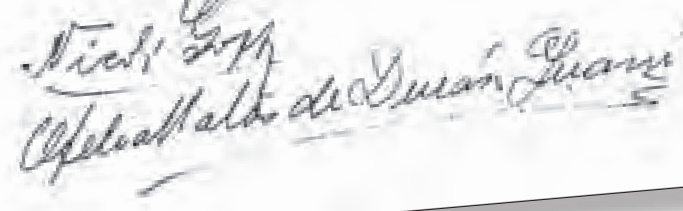


La Cumparsita: una fuente de pleitos

Contursi y Maroni vs. Matos Rodríguez

"La Cumparsita": a source of lawsuits

Contursi and Maroni vs. Matos Rodríguez

in crescendo, fue reafirmando su popularidad y su éxito y alcanzó una difusión y una asombrosa preponderancia sobre los demás tangos de su época, constituyendo un suceso sin precedentes que todavía se mantiene en pleno apogeo, incluida en el repertorio de todas las orquestas típicas. Impuesto también en París y en los más importantes centros de Europa y de América (Canaro 1999: 244 y siguientes)".

Para comprender la decisión de Canaro, y para compartirla o no, sería necesario situarse en 1948 y oír algunas de las versiones del momento. Por ejemplo podría oírse la grabación de Carlos Gardel realizada en Barcelona el 10 de enero de 1928 en los estudios de Odeón, y ya con el sistema eléctrico, para luego oír alguna versión instrumental de calidad; no de las primeras de 1917, de Alonso-Minotto, Firpo o Maglio, que suenan muy viejas en calidad técnica, sino por ejemplo la del guitarrista Oscar Alemán de 1928, la de la Orquesta Típica de la Victor de 1932 o la de la Orquesta de Francisco Lomuto de 1936. Después de oído esto, como condición imprescindible, se tendría base suficiente para opinar sobre el acierto o el desacierto de Francisco Canaro.

De ese laudo lo que nos va importar es la regulación que para el futuro hace del reparto de los derechos de autor, pero contiene alguna previsión respecto del pasado, de la que se ha aquí simple mención:

a) Lo percibido por Matos con anterioridad a la iniciación del proceso quedó incorporado a su patrimonio y de todo ello nada corresponde a los demandantes. Esto es, lo pasado está pasado y no se vuelve atrás. La iniciación del proceso en 1946 marca un antes y un después. Lo de antes ya no tiene remedio.

b) En el proceso de Contursi y Maroni contra Matos se había pedido por los demandantes medidas cautelares y se habían acordado por el Juzgado. La medida cautelar consistió en el embargo preventivo del 40 por 100 de las cantidades que debía abonar SADAIC a Matos y sobre esas cantidades se hace un doble pronunciamiento:

i) Del primer embargo, por monto que desconocemos ${ }^{(28)}$, la cantidad resultante se abonará a los demandantes Contursi y Maroni, si bien estos deberían abonar a Razzano la cantidad de 5.000 pesos moneda nacional. Esta es la compensación a Razzano por desistir de su proceso. Con ello Razzano queda fuera de los derechos de autor de La cumparsita, se entiende sin perjuicio de lo que pudiera corresponderle por la grabación de Carlos Gardel hecha en Barcelona en 1928 y en tanto intérprete.

ii) La cantidad del segundo embargo se repartiría ya entre los autores de la letra y el autor de la música conforme a lo que se dice seguidamente.

Hasta aquí el laudo lo que hace es cerrar lo pasado. Lo que importa es el futuro.

\section{El Convenio de 1952 para aclaración del laudo}

Ya hemos advertido que en el arbitraje faltaba alguien. Matos había vendido su tango en 1917 y, aunque se habían sucedido contratos en 1926 y en 1933, el caso seguía siendo que la Editorial Ricordi tenía algo que decir y que no había sido oída ni en el proceso ni en el arbitraje. Esto motivó un convenio posterior, firmado el 10 de diciembre de 1952 en el que las partes anteriores, con el añadido de Ricordi, llegan lo que se llama convenio de aclaración del Laudo de Canaro.

(28) El monto total del embargo era de 84.657'16 moneda nacional argentina. En el escrito inicial del expediente de sucesión de Gerardo Matos tramitado en Buenos aires (y que tenemos a la vista) dice el abogado del estudio de Pablo Calatayud que lo firma, el doctor Luis B. Joselevich, que el total del embargo era de 35.208'19 moneda nacional y que se debe dejar constancia de este importante dato a la hora de sucesión. Pero como el tiempo fue pasando el mismo abogado el 12 de julio de 1950 dijo por escrito de esa fecha que el importe era ya de 84.657'16 moneda nacional argentina y que los actores habían percibido 55.863'85 moneda nacional. 


\section{Juan Montero Aroca}

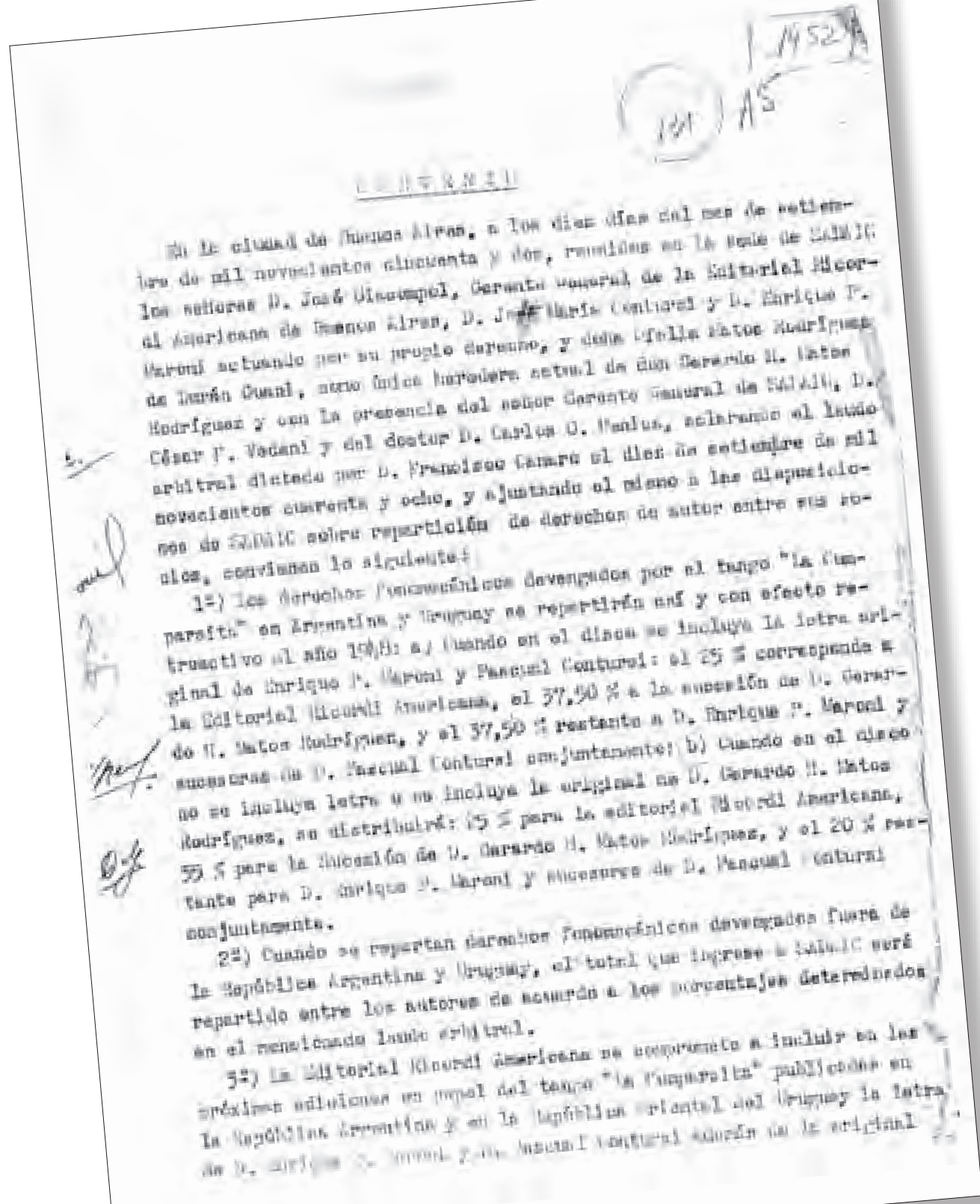


La Cumparsita: una fuente de pleitos

Contursi y Maroni vs. Matos Rodríguez

"La Cumparsita": a source of lawsuits

Contursi and Maroni vs. Matos Rodríguez

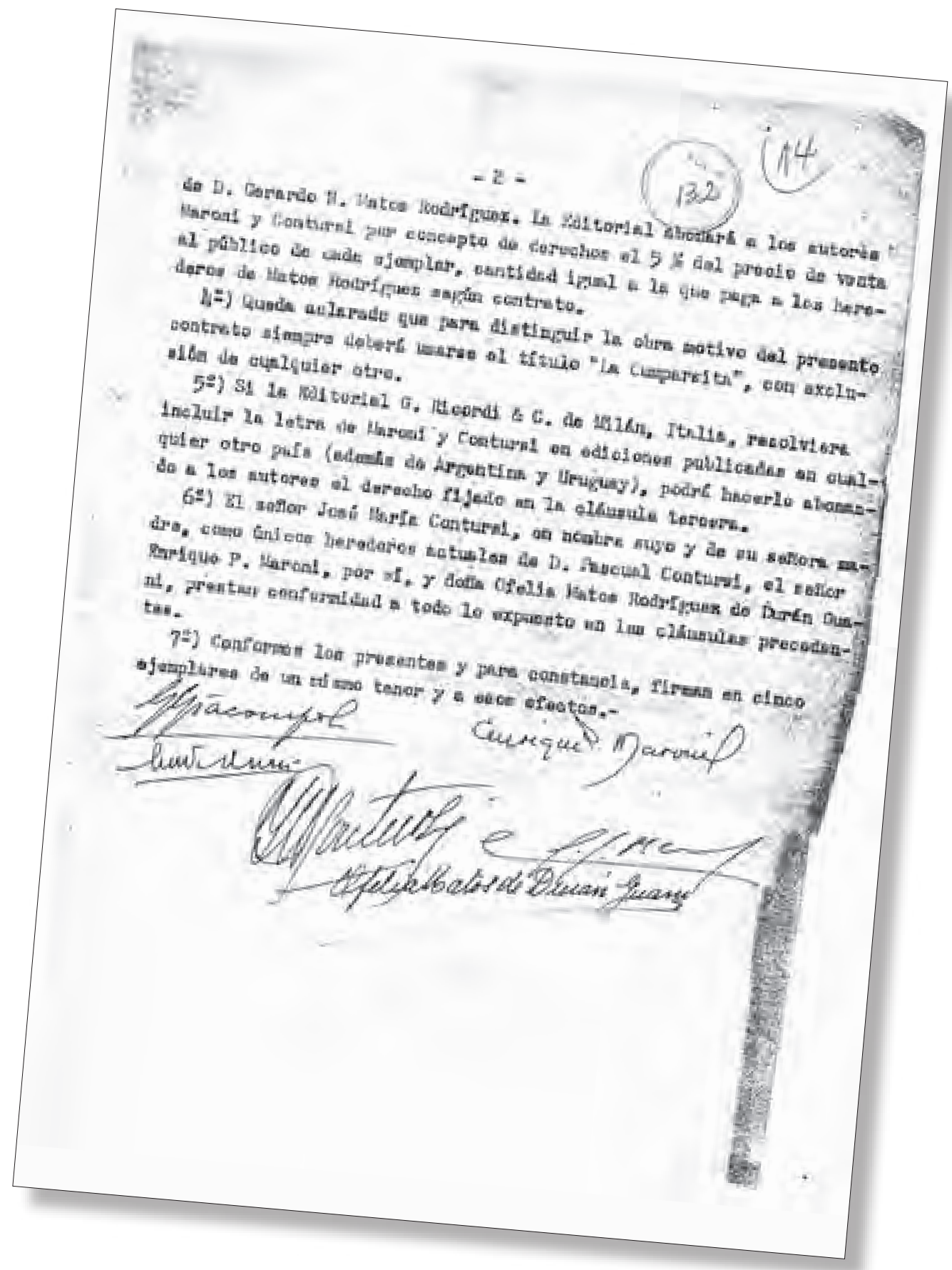




\section{Juan Montero Aroca}

El contenido del Laudo de 1948 y del Convenio de 1952 puede requerir alguna explicación y por ello pueden ser de utilidad los detalles siguientes:

a) Derecho de ejecución, el derecho derivado de la mera ejecución pública del tango, en cualesquiera lugares, desde bailes hasta televisiones, le corresponde a los autores de la letra el 20 por 100 de todo lo que devengue en el futuro La cumparsita, de modo que a cada uno de ellos le corresponde el 10 por 100. Adviértase que no se dice que ese tanto por ciento se refiere al supuesto de que el tango se ejecute con la letra de Contursi y Maroni, sino en todo caso, aunque la ejecución sea únicamente instrumental. Cada vez que el tango suene en el mundo -por lo menos en los países civilizados que protegen los derechos de autor- los autores de la letra tienen derecho al 20 por 100 , se entiende conjuntamente, de lo que se perciba como derechos de autor.

b) Derecho de inclusión en películas se divide de esta manera:

b.1) Cuando se utilice la letra de Contursi y Maroni se estará a las normas reconocidas por la SADAIC, que normalmente dividian los derechos al 50 por 100.

b.2) Si no se utiliza la letra, es decir, si sólo se utiliza la música, entonces se estará a que los letristas les corresponderán el 20 por 100.

c) Derechos fonomecánicos, los relativos a los discos: Se procede a distinguir según el origen de los discos:

c.1) Los derechos devengados en Argentina y en Uruguay se repartirán de este modo y con efecto desde 1948: (i) Si en el disco se incluye la letra de Contursi y Maroni el reparto es éste: 25 por 100 a Ricordi, 37'50 por 100 a los sucesores de Gerardo Matos y 37'50 por 100 conjuntamente a Maroni y a los sucesores de Contursi; y, (ii) Pero si en el disco no se incluye letra alguna o se incluye la letra de Matos Rodríguez: 25 por 100 para Ricordi, 55 por 100 para sucesores de Matos y 20 por 100 con juntamente para Maroni y sucesores de Contursi.

c.2) Derechos devengados en todos los demás países: Todo lo que ingrese la SADAIC se repartirá según el laudo, es decir, si se utiliza la letra de Contursi y Maroni se dividirán los derechos al 50 por 100 y si no se utiliza esa letra a Maroni y a los sucesores de Contursi les corresponde conjuntamente el 20 por 100. Esto es muy importante por cuanto que en la actualidad los sucesores de Contursi y Maroni siguen percibiendo de todos los discos instrumentales de La cumparsita el 20 por 100 , pero si se incluye la letra (caso por ejemplo del disco de tangos de Julio Iglesias) entonces perciben el 50 por 100 de los derechos generados y que haya recaudado la entidad argentina.

d) Para el derecho de edición también se distingue:

d.1) Si se trata de Argentina y de Uruguay de entrada la Editorial Ricordi Americana se comprometió a incluir en las partituras publicadas las dos letras, la de Maroni y Contursi y la de Matos Rodríguez, confirmando lo dispuesto en el laudo. En este caso la Editorial debía pagar a Maroni y a los sucesores de Contursi el 5 por 100 del precio de venta al público, que es lo mismo que ya pagaba a los sucesores de Matos Rodríguez ${ }^{(29)}$.

d.2) Para todos los demás países la Editorial G. Ricordi \& Co. de Milano no se comprometía a incluir en todo caso la letra

(29) Cuando en 1998 el Parlamento uruguayo declaró que La cumparsita era Himno Cultural y Popular de la República Oriental del Uruguay se cuidó mucho de aclarar que esa declaración "comprende únicamente la música, no alcanzando las letras que se hubieren agregado a la referida pieza musical”. De este modo, la letra de Pascual Contursi, argentino, no tiene proclamación alguna, cierto, pero tampoco la tiene la del uruguayo Gerardo Matos. 
La Cumparsita: una fuente de pleitos Contursi y Maroni vs. Matos Rodríguez "La Cumparsita": a source of lawsuits Contursi and Maroni vs. Matos Rodríguez de Contursi y Maroni, dado que no estaba obligada a ello, pero en el caso de que la incluyera debería abonar a Maroni y a los sucesores de Contursi el 5 por 100 del precio de venta al público.

Y hasta aquí un arduo problema jurídico al que pusieron fin primero el laudo de Canaro y, luego, la sensatez de todos los implicados. Lo que no se pudo hacer en vida de Gerardo Matos se acabó haciendo después de muerto. $Y$ ahora queda una cuestión de hecho que cada uno debe decidir por sí: ¿la letra de Pascual Contursi añadió algo a la música de La cumparsita? ¿Algo que mereciera ser retribuido como lo ha sido y como lo sigue haciendo?
Cada uno tiene su respuesta. No la verdad, sino simplemente su verdad.

\section{Referencias Bibliográficas}

Bates, Luis y Héctor. 1936. Historia del tango. Buenos Aires.

Canaro, Francisco. 1999. Mis memorias. Mis bodas de oro con el tango. Buenos Aires: Editorial Corregidor.

Infantozzi, Rosario. 2004. De Matos Rodríguez, La cumparsita. Montevideo: Doble clic Editoras.

Montero Aroca, Juan. 2010. La cumparsita. Vida y Derecho en el tango más universal. Valencia: Tirant.

Puccia, E. H. 1997. El Buenos Aires de Ángel G. Villoldo (18601919). Buenos Aires: Editorial Corregidor. 